\title{
Growth responses to competitive shocks: market structure dynamics under liberalisation
}

Article

Accepted Version

Kambhampati, U. S. and Kattuman, P. A. (2009) Growth responses to competitive shocks: market structure dynamics under liberalisation. Structural Change and Economic Dynamics, 20 (2). pp. 114-125. ISSN 0954349X doi: https://doi.org/10.1016/j.strueco.2009.01.002 Available at https://centaur.reading.ac.uk/17934/

It is advisable to refer to the publisher's version if you intend to cite from the work. See Guidance on citing.

Published version at: http://dx.doi.org/10.1016/j.strueco.2009.01.002

To link to this article DOI: http://dx.doi.org/10.1016/j.strueco.2009.01.002

Publisher: Elsevier

All outputs in CentAUR are protected by Intellectual Property Rights law, including copyright law. Copyright and IPR is retained by the creators or other copyright holders. Terms and conditions for use of this material are defined in the End User Agreement.

www.reading.ac.uk/centaur 
Central Archive at the University of Reading

Reading's research outputs online 


\section{Growth response to competitive shocks: Market structure dynamics under liberalisation - the case of India}

by
Uma S. Kambhampati Department of Economics University of Reading
Reading
RG6 6AH
United Kingdom

Tel: 01189875123 ext. 4248

E-mail: u.s.kambhampati@reading.ac.uk
Paul A. Kattuman

Judge Business School University of Cambridge

Trumpington Street

Cambridge CB2 1AG

United Kingdom

Tel: 01223764136

E-mail: p.kattuman@jbs.cam.ac.uk

Acknowledgements: We are grateful to Peter Hart and M. Anand Rao for very useful comments.

Corresponding Author: Paul Kattuman

Suggested running head : Market structure dynamics 
Growth response to competitive shocks: Market structure dynamics under liberalisation the case of India

\begin{abstract}
Liberalisation transforms market structures through the responses of incumbent firms and entrants to freedom of choice. As market shares turn more volatile, the agility of small and large firms will determine changes in market structure. We analyse these processes for Indian manufacturing industries over the 18-year period from 1980, spanning the liberalisation of 1985 and more comprehensive reforms of 1991, using a data set of large and medium firms in 83 industries. We find that large changes in turbulence in market shares, and in the way firm growth was related to size tended to offset one another, producing deceptively little change in market structure itself.
\end{abstract}

JEL Codes: L19, L60, C21, C22

Key words: Liberalisation, Competitive Shocks, Firm growth, Turbulence, Market structure, India 


\section{Introduction}

This paper analyses changes in market structure in the context of significant structural and policy shifts. Much of the analysis of market structure in Western market economies concentrates on relatively mature, stable industries. Patterns of change in such industries are likely to be very different from those in dynamic and fast growing industries in transitional economies. The paper makes two key contributions to the literature. First, it provides a novel decomposition of market structure changes into two components - the changes caused by the mobility of firms in each industry across the size ranking and the changes that are related to the size of the firms. This extends earlier decompositions (Davies and Geroski, 1997) by pinning down the joint evolution of market share turbulence and size-related growth in the context of a full distribution measure of concentration - the Hirschman Herfindahl Index. Secondly, the application of this analysis is particularly illuminating in the context of a developing, transitional economy.

A key intended result of greater freedom conferred upon firms to choose competition strategies is readier market selection - whereby efficient firms enter and grow by investing to enhance capabilities, productivity and quality, while less efficient firms contract and exit. New investments, depending on their magnitude and effectiveness, should lead to changes in the configuration of market shares. There may be a "noisy" flurry of activity that follows liberalisation, but deeper patterns of adjustment, in terms of exit or contraction of the inefficient and entry and growth of the efficient, should win through as the dust settles. However, liberalisation will also mean fiercer battles for market shares, and one should expect less stability in the configuration of market shares.

Which types of firms respond to the new found freedom in terms of growth? The best practice technology in each industry will determine whether they are small firms or large. In some industries, small firms hitherto sheltering behind regulations may turn out to be the more agile and successful in gaining market shares. In others, particularly those where economies of scale derive from the critical nature of advertising and $R \& D$, unwinding regulations may permit large firms to outrun small. Growth responses will also depend on the scope of liberalisation. Limited domestic liberalisation that frees domestic firms, shielding them from international competition could favour larger domestic firms. Liberalisation of trade and foreign investment, subjecting domestic firms to international competition may be harsher on the largest firms if they do not restructure rapidly. As competition increases sharply, market shares may grow volatile and gainers of market shares will be less able to maintain them as a matter of course.

At the heart of our analysis is a reconciliation of divergent aspects in market structure dynamics. '.. Changes in concentration occur slowly with high or low levels of concentration persisting for relatively long periods of time. On the other hand, ... [it is common to find]... large changes of shares which sometimes occur over short periods of time among the group of leading firms." (Davies and Geroski, 1997, p.383). The intuition is that when market shares of firms change, some of the changes offset each other in the calculation of concentration. This may happen, for example, if firm A and firm B trade places in the share rankings even though their absolute market shares do not change. This will leave the concentration ratio unchanged in spite of there being significant mobility within the industry. Which aspect captures the true picture of competitive rivalry (Davies and Geroski, 1997)? ${ }^{1}$ 
Liberalisation episodes, when competitive rivalry increased, are a suitable context to revisit this question. Using data from an interesting period, we use a simple decomposition framework to examine how changes in market concentration related, on the one hand, to market share churning and, on the other, to the degree to which large (or small) firms gained market shares systematically. We examine these distinct component elements of market structure changes in the context of two episodes of reforms in India. The first, dated at 198586 , involved limited domestic deregulation. In contrast, the reforms of 1991 were far reaching and encompassed substantial opening up to the international economy. We look at the growth responses of medium and large firms in a set of 83 manufacturing industries (defined at the SIC 3 digit level) over a period 1980 to 1998, and examine the impact of the very different types of shocks to the business environment in 1985 and 1991.

By way of background, the main features of the two phases of liberalisation are outlined in the next section. In section 3, we set out a framework for our analysis and review issues in market structure dynamics. Section 4 describes the data and provides a preliminary characterisation of the variables of interest. Section 5 sets out our econometric model that is estimated in a panel framework. The results are discussed in section 6, with an assessment of the dynamics of the components of market structure change, in relation to each other and to their total. Section 7 concludes.

\section{Background}

\subsection{Liberalisation in India: 1985 and 1991}

Till the mid 1980s India followed a strategy of planned economic development based on import substitution. The 1951 Industrial Development Regulation Act had set out the basic cast and machinery of industrial policy. This involved a comprehensive regulation of the direction and volume of investment through licenses, a large public sector, and foreign exchange controls. Planned import substitution tilted investment flows initially towards heavy and capital goods industries and later towards chemicals, petroleum and durable consumer goods. It is now universally accepted that this highly regulated and protectionist regime spawned a sluggish and high cost manufacturing system that was also dynamically inefficient (Bhagwati and Desai, 1970; Bhagwati and Srinivasan, 1975; Ahluwalia, 1985).

In 1985, the Rajiv Gandhi administration (1984-1991) crystallised the logic for reducing the stranglehold of regulation that had been gathering strength over time, into the first, though modest, effort to rejuvenate the industrial system in over forty years. These reforms, collectively termed the New Economic Plan, but more accurately characterised as liberalisation by stealth, eased entry and expansion of incumbent firms by de-licensing capacity expansion for many classes of firms: firms with assets below a moderate threshold; those located in "backward" areas; firms in scale-critical industries, and firms that were "modernising". Modernisation was encouraged through relaxing controls on import of capital equipment and technical know-how. Licenses were "broadbanded" to allow enterprises to adjust their product mixes more easily to changing market conditions. There was some relaxation of the restrictions on "monopoly houses", if their expansion were in "priority industries". (Economic Survey, 1985/6; Srivastava, 1996). These initiatives generally increased the freedom of incumbent firms to expand. Encouragement of de-novo entry was less effective. 
The second phase of reforms, which was part of the substantial structural adjustment programme of 1991 under IMF injunctions, was more radical. New Industrial policy lifted the rules of investment licensing. Restrictions on expansion by monopoly houses were relaxed, rules of foreign investment relaxed, and sectors reserved for the public sector were thrown open to private sector entry and competition. ${ }^{2}$ Trade liberalisation was just as significant. Procedures for foreign direct investment were simplified and trade tariffs reduced. The maximum import tariff was reduced to 40 percent from a high of 340 percent. Quantitative restrictions were eliminated for capital and intermediate goods. The substantial thrust of 1991 reforms was to expose incumbent firms to greater competition, particularly international competition, but also from new entrants.

The relative strengths of the reform episodes of the mid Eighties and the Nineties and the difference they created in terms of observed growth has been debated. Panagariya (2004) taking issue with deLong (2001) concludes that the former were "limited in scope and without a clear roadmap", but they laid the basis for the reforms in the 1990s which were "more systematic and systemic".

\subsection{Literature}

Most studies of changes in market concentration fall into the traditional industrial organisation (IO) framework, wherein changes in market concentration are seen as determined by a number of other industry-level behaviour and performance variables. In this paper, we deviate from this literature by decomposing the changes in market concentration into 2 components and by also considering the factors that influence each of these components. As indicated earlier, this derives much from Davies and Geroski (1997) who decompose the concentration ratio into the sum of market share changes and net entry. We will return to this in the next section.

In terms of changes in industry, the somewhat hesitant mid 1980s liberalisation has not come under much scrutiny, followed as it was by the radical 1991 reforms. $^{3}$ Srivastava (1996) and Chand and Sen (2002), both focus on productivity: firms increased their use of imported raw materials, and labour productivity and capital intensity increased. Srivastava reports clear evidence of reallocation of resources at the sectoral level ${ }^{4}$; Chand and Sen find significant increase in total factor productivity growth.

Basant (2000) provides an analytical narrative of corporate responses to the reforms of 1991. Multinational Enterprises (MNEs) offered significant competition to domestic incumbents, engaging in mergers and acquisitions to enter Indian markets. In response, domestic firms have been vigorous in attempts to restructure and consolidate in chosen areas. Domestic firms clearly needed to improve organisational and technical efficiencies to survive, while MNEs needed to invest in building local distribution networks (Patibandla, 2002). Chandra and Sastry (1998) report the results of a survey that found firms making significant attempts to upgrade manufacturing capability. More firms have come to rely on imported technology, and a larger number of firms have embarked on export based growth paths.

Ghemawat and Khanna (1998) report on two case studies of the responses of diversified Indian business groups to the reforms of 1991 . With the sudden increase in competitive intensity their chosen subject business groups undertook tremendous restructuring, involving staged re- 
focussing of business portfolios using a variety of partial and complete exit and entry options. One of the important pointers for large sample work on corporate responses to liberalisation identified by their case studies is the need to allow for lags in the process showing results.

Close in spirit to the current study is the work of Ghemawat and Kennedy (1998) who examined the impact of sudden and simultaneous liberalisation in Poland along many fronts (the "big bang" of 1 January, 1990, encompassing foreign trade, FDI, prices, and regulations on entry, exit and factor markets) on market structure. They highlighted the disequilibrium dynamics and the need to note distortions in pre-shock structure and the lags in adjustment to new equilibrium after the sudden increase in the role of market forces. Drawing on Sutton $(1991,1998)$ they explained the deconcentration of many markets after competitive shocks in terms of adjustment from an initial disequilibrium to new equilibrium levels that (given high levels of initial concentration) were lower. Sutton's bounds approach also suggests that the adjustment will depend on the structural attributes of the industry: the lowest sustainable levels of concentration will increase with advertising, R\&D and asset intensity.

\section{Market Structure Dynamics: Growth and Turbulence}

\subsection{Concentration, Mean Reversion and Mobility: A decomposition scheme}

The Demsetzian hypothesis that the growth and performance of efficient firms is the proximate cause of increases in market concentration could be extended to the context of liberalisation: efficient firms may grow faster under liberalisation, particularly in industries characterised by economies of scale wherein this growth will further increase efficiency. The implication is that industries marked by economies of scale will see higher levels of concentration relative to those without economies of scale. Patibandla (1998) argues that small and medium scale firms were found to be more efficient than large firms in the pre reforms period with their growth being constrained only by capital market imperfections and market transaction costs. These imposed imposed mobility and entry barriers on these firms. Extending his analysis, we argue that if reforms did reduce capital market imperfections, we might expect efficient small firms to have increasingly contested the market positions of inefficient large firms and to have grown on the strength of their higher production efficiency. On the other hand, if small firms faced greater difficulty in obtaining external finance, as some have argued with the share of bank credit to small firms (categorized as small scale industry), having actually declined (Rao, 2005), then liberalization may not have reduced capital market imperfections faced by small firms. The net effect is uncertain. If efficient small firms grow, then the size distribution will grow more equal in the short run.

However, the structural shock of liberalisation has been accompanied by the inevitable myriad of random shocks in the market environment - firm specific, industry wide or economy wide. Observed patterns in the evolution of market shares will reflect firm reactions to random shocks as well as structural shocks. What would be useful is a framework that pins down the joint evolution of market share turbulence and size-related growth. This would address the 'disjunction' noted by Davies and Geroski (1997) " . . . between studies of . . . industrial concentration and the studies of market shares of individual firms . . Even the obvious link, via aggregation of market shares ... has been insufficiently explored". 
Full distribution measures of concentration permit simple exact decompositions of concentration change into components that relate to turbulence and size related growth. Consider a set of firms in a cross section, indexed by $\mathrm{i}$, and the variable of interest, firm size denoted by $\mathrm{s}$. For individual $\mathrm{i}$, change in size over time is by definition, $s_{i t} \equiv s_{i t-1}+\Delta s_{i t}$. If market concentration, the cross section distributional feature of interest is measured by the real valued function of the vector of market shares, say $\mathrm{f}\left(\mathrm{s}_{\mathrm{t}}\right)$, then $f\left(\mathbf{s}_{\mathbf{t}}\right) \equiv f\left(\mathbf{s}_{\mathbf{t}-\mathbf{1}}+\Delta \mathbf{s}_{\mathbf{t}}\right)$. If the statistical function $\mathrm{f}($.$) is$ additive in the sense that it can be written: $f\left(\mathbf{s}_{\mathbf{t}}\right)=f\left(\mathbf{s}_{\mathbf{t}-1}\right)+f\left(\Delta \mathbf{s}_{\mathbf{t}}\right)+g\left(\mathbf{s}_{\mathbf{t}}, \Delta \mathbf{s}_{\mathbf{t}}\right)$ the cross sectional feature measured by $\mathrm{f}($.$) increases with f\left(\Delta \mathbf{s}_{\mathbf{t}}\right)$, a summary measure of all changes of market shares, and $g\left(\mathbf{s}_{\mathbf{t}}, \Delta \mathbf{s}_{\mathbf{t}}\right)$, a summary measure of the systematic relationship between current market shares and changes in market shares.

In this paper we work with the Hirschman-Herfindal index. The HHI has the advantage in common with other full distribution measures of concentration, of reflecting both the size inequality and firm numbers in the industry. It is one of the most commonly used measures and is therefore well understood. If the size share of firm i, is represented by $s_{i t}$, and the vector of market shares is $\mathrm{s}_{\mathrm{t}}$, then $\mathrm{HHI}$ at time $\mathrm{t}$ is defined as $\mathrm{H}\left(\mathrm{s}_{\mathrm{t}}\right)=\Sigma_{\mathrm{i}}\left(\mathrm{s}_{\mathrm{it}}\right)^{2}$. HHI at time $\mathrm{t}$ is: ${ }^{5}$

$$
H H I_{t}=H H I_{t-1}+\sum_{i} \Delta s_{i t}^{2}+2 \sum_{i} s_{i t-1} \Delta s_{i t}
$$

The third term in the RHS of (1) is a measure of the linear association between initial market share and change in market share. This term (SGRT) weights the change in market share of each firm with its starting market share. Thus it gives greater weight to market share changes of large firms. This term captures the hypothesis commonly presented as Gibrat's Law, and which has been reviewed in detail in Sutton (1997). If the size-growth term is significant, then of course growth is related to size and therefore Gibrat's Law is rejected. If it is not significant, then we can argue that Gibrat's Law holds. A negative SGRT will imply that small firms have, on average, gained relative to large. ${ }^{6}$

The second term in the RHS of (1), $\sum_{i} \Delta s_{i t}{ }^{2}$, is a measure of market share turbulence, or mobility, (MOB) (Cable, 1997). MOB is a measure of gross change in market shares, and picks up both increases and decreases in market shares. ${ }^{7}$ This concept of mobility differs from the notion that Sutton(1997) describes as turbulence.

Therefore:

$$
\Delta H\left(\mathbf{s}_{t}\right) \equiv M O B+S G R T
$$

This identity decomposes the change in concentration into a systematic size related growth component, and another, total intra-distributional mobility component. This decomposition a novel one, though it does derive from similar ones in Cable (1997) and Davies and Geroski (1997). The Davies and Geroski decomposition was itself derived from Weiss (1965) where the concentration measure being decomposed is the concentration ratio and seen as composed of the sum of market share changes of surviving firms (SUR), the joint market shares of 
entrants into the top 5 in year $\mathrm{t}+1$ (ENT) minus the joint market shares of exitors out of the top 5 in year $\mathrm{t}+1$ (EXT).

\subsection{Conjectures on market structure dynamics}

In a liberalised environment, the market selection process should, in course of time, highlight any systematic differentials in the abilities of firms to pick up and leverage market opportunities while withstanding competition. If the capable firms are the small ones, we would expect that market share movement takes the form of small firms gaining share relative to large, and therefore a reduction in concentration. If the efficient firms were the large ones we would expect large firms to increase their market shares, and increased concentration. The overall argument implies that technological economies of scale determine the long run market concentration.

But models of market structure highlight the way firm behaviour ("conduct") in pursuit of market power successfully maintains concentration at high levels. By increasing firm choice liberalisation reinforces the role of firm level efforts (to enter, to prevent entry, and to compete with others in the market). The corollary is that attained market shares are under fiercer challenge, and competitive shocks may increase the volatility in market shares. Increase in mobility ipso-facto, increases concentration, ${ }^{8}$ and since turbulence is an indicator of competitive rivalry, increase in concentration is not a negative development. Increases or decreases in concentration only carry information on whether, on balance, small firms or large are winning in the market.

The immediate response of potential entrants and incumbents to a relaxation of constraints could be increased investment, employment, $\mathrm{R} \& \mathrm{D}$, import or export activity, in various combinations. The heightened tempo of competitive activity might translate into an initial phase of increased turbulence in market shares, which should cloud around the underlying systematic adjustment process of industries moving from (relatively stable) pre-liberalisation market concentration levels, to equilibrium market structures in the new environment. The pre-liberalisation configuration was relatively stable, and has been characterised as a disequilibrium, based as it was on a pervasive command and control system. For each industry, the speed of adjustment is likely to depend on the deviation of this pre-liberalisation concentration level from the post-liberalisation equilibrium.

The implications of domestic liberalisation should be different from those of comprehensive liberalisation. Till the mid 1980s, industrial, trade, public sector, foreign investment and foreign exchange policies constrained and protected firms from internal and external competition, and directed their efforts towards rent seeking and lobbying. Small-scale sector policies prevented firms from reaching economies of scale in many sectors. In the new climate of domestic freedom created by the reforms of 1985-1986, incumbent firms would have been at an advantage in gaining market shares. If firms had been held back from the scales of the best practise technology, one might have expected them to grow. In industries where advertising and $R \& D$ are natural instruments of vertical product differentiation, large firms may have the relative advantage and firm level "escalation" of endogenous sunk cost investments could have led to increases in market concentration. 
There has been significant new entry in Indian industry after the 1991 liberalistion, particularly MNCs with superior technologies compared local firms (Patibandla, 2002). When foreign firms gained substantial access to the domestic market in 1991, large Indian firms clearly began paying more attention to upgrading capabilities, and product differentiation through increased advertising, $R \& D$ and marketing expenditures, but it is not clear that these efforts were sufficient to meet the competitive challenge (Basant and Chandra, 2002). Sutton's model $(1991,1998)$ predicts that the resulting equilibrium after a sudden and sharp increase in the toughness of competition could be an increase in concentration after a shake out of the laggards in restructuring. The dataset available to us includes entrants and $\mathrm{MNC}$ firms but does not allow the analysis of their separate effects (see section 4).

In summary, liberalisation can lead to interesting patterns in the dynamics of two components of market structure. In each industry, the market share volatility will cloud the structurally based, systematic growth response of firms, small and large, that depends on the advantage or disadvantage of size in the new competitive milieu. To understand the change in market structure we need to disentangle the contribution of the size related growth component from that of the market share volatility component, and assess their separate dynamics.

\section{Data}

The data used in this paper is the Reserve Bank of India (RBI) compilation of firm level profit and loss accounts and balance sheets of the large and medium, non-government, non-financial, public limited companies registered in India. The data relate to individual companies, which may be parts of much larger industrial houses, but are legally separate entities, independent in their day-to-day operations. These companies fall in 83 three-digit industries. The assignment is based on majority ( $>50 \%$ ) output $^{9}$. We use data for the period 1980-1998.

The RBI data comes from a purposive sample designed to adequately represent companies belonging to different industry groups and size classes. The sample size is relatively large both in terms of numbers (and in terms of paid-up capital - accounting for nearly $65 \%$ of the total paid-up capital of the entire population of public limited companies). On average there were 23 firms per industry per year, ranging from a maximum of 132 firms, to a minimum of a single firm. The size of the sample in terms of number of companies has been increasing over the years, and over $75 \%$ of companies are retained from one year to the next ${ }^{10}$.

Firms however can fall out of this panel for a couple of reasons. They may not be sampled; they may fail to meet the size requirements; third, they may fail to submit their returns to the RBI. In an analogous manner, when firms enter the dataset, they may not reflect new entry. Thus they may be: firms that have just reached the size threshold; firms that fell out because they did not submit their returns and are now doing so. Given this, it is not possible to distinguish "births" and "deaths" from the changing sample composition. This is one clear limitation of the data available ${ }^{11}$ and must be taken into account in interpreting our results. Likewise, RBI data includes firms that are foreign owned, and entrant MNCs but they are not separately identified. Thus while MNCs and new entrants are not excluded from our analysis, we are unable to delineate their separate effects. Another limitation of the data is that it is restricted to large/medium firms, a restriction that could cause the HHI to be biased upward. 
For the purposes of computing the indices of concentration, size-growth and mobility, we constituted two-year rolling panels of firms from the data. For each of the industry specific explanatory variables, we computed annual median values across all firms in the industry from the first years of the rolling panels - the means were affected by outliers. The panel of median values constitutes our data on explanatory variables.

The table A1 in the Appendix presents the summary statistics for the variables of interest in the pre-liberalisation and post-liberalisation periods. Even in terms of the means across years and industries (within the pre and post-liberalisation periods), the proportionate changes in the sizegrowth component (SGRT) and the mobility (MOB) component are high relative to the change in concentration (HHI). For variables (the reported values are means over the years and across industries, of the year-industry median firm values) such exports, advertising and R\&D as ratios to sales, as well as growth rates and profitability that capture forces that drive market structure, the domestic liberalisation period saw sharper increases relative to the pre-liberalisation period, followed by a some declines in the post-1991 period.

Our focus in this paper is on understanding real economic processes that underlie changes in market concentration, and on assessing their relative magnitudes in domestic as against comprehensive liberalisation. It must be re-iterated that the data does not permit us to estimate true levels of market concentration; the purposive sampling frame is designed to provide coverage only of large and medium firms. This data set is the most comprehensive one spanning the period of interest; the selective coverage does mean that the results we report are specific to this population.

Figure 1: Concentration change, Size-Growth and Mobility: Printing Industry

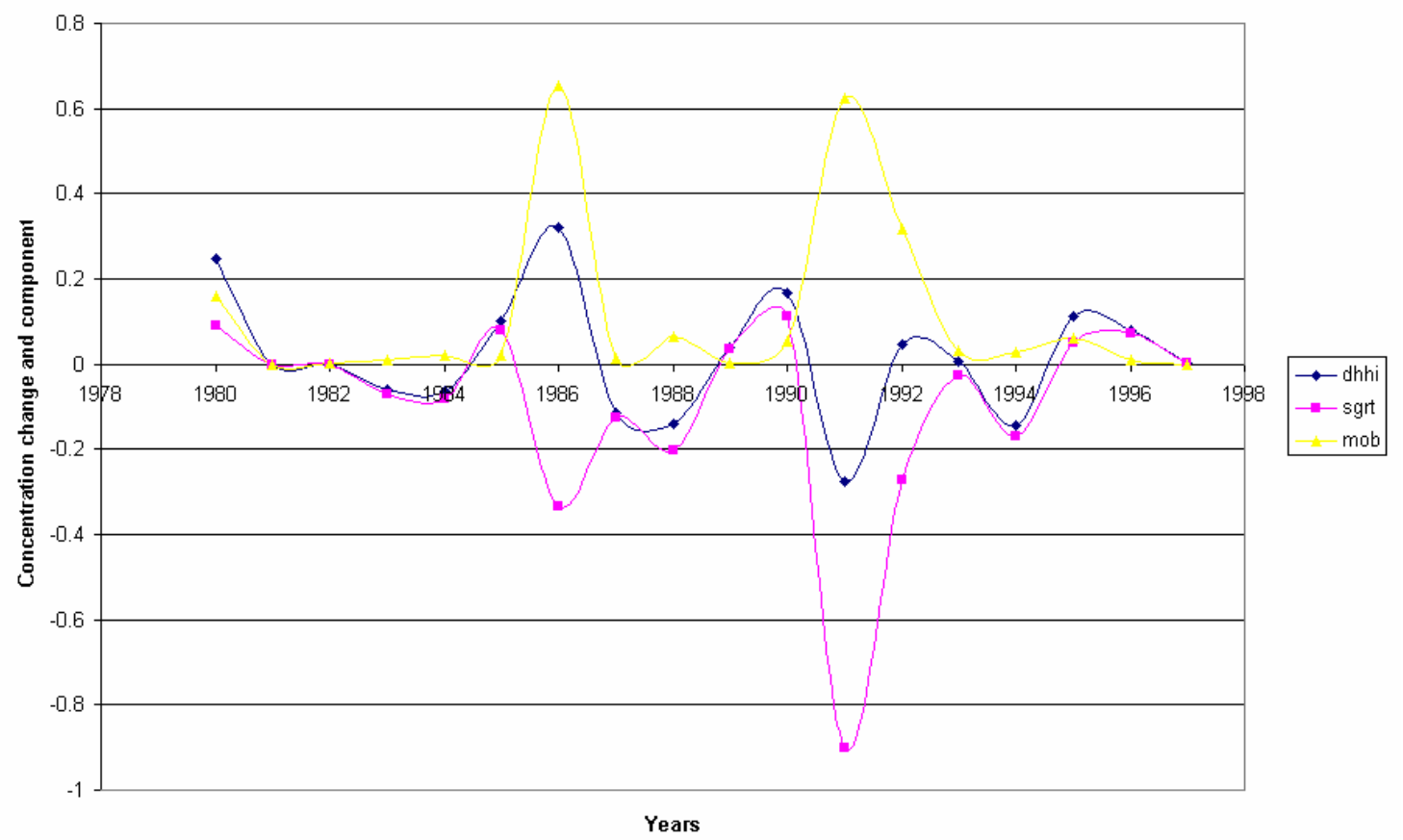


Figure 1 above uses data on the printing industry alone to illustrate the way in which the underlying processes, (the way growth is related to size, and market share turbulence) responded to the different liberalisation episodes. When liberalisation was partial and domestic, mobility (MOB) shot up and small firms grew relative to large, leading to a reduction in the size-growth component (SGRT). In the comprehensive liberalisation episode, again this was repeated. In both cases they tended to offset each other, leading to lower visible change in market structure itself.

The tendency of the components to offset each other is illustrated in figure 2. Here we have plotted all industry-year data points for SGRT, MOB and $\triangle \mathrm{HHI}$, ordered descending according to $\Delta \mathrm{HHI}$, irrespective of industry or year. The scatters are summarised by simple polynomial trend plots. It is obvious that the underlying processes offset each other and in the majority of cases, produce changes in market structure that are much smaller than the components themselves.

Figure 2 : Change in Concentration and Components: Size Growth and Mobility

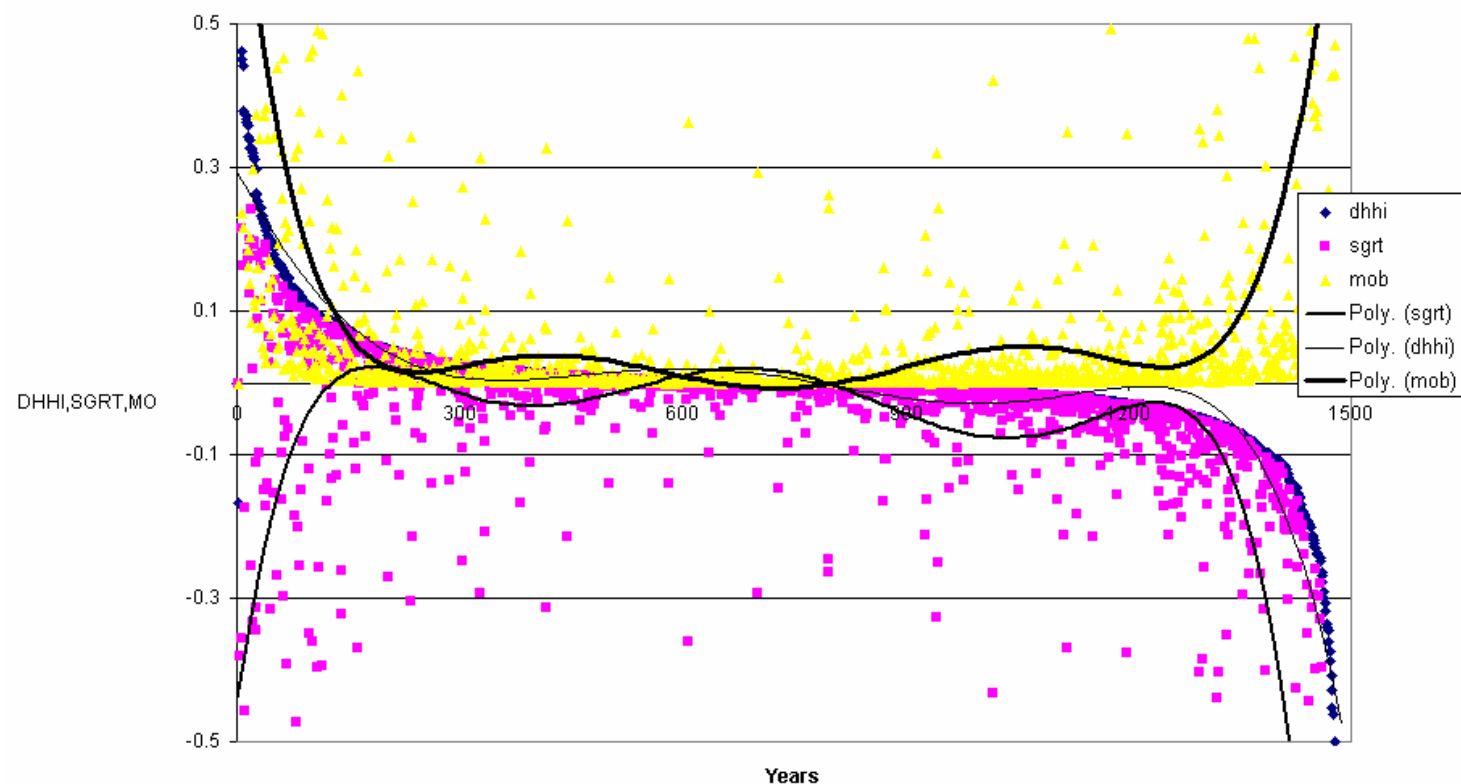

\section{Estimation}

Capital intensity, advertising and R\&D intensity have been identified as significant determinants of market structure in many empirical IO studies. In addition, the rate of growth of the market and export propensity have also been seen to matter. The standard method of explaining market structure would be to estimate a model for concentration including the above as explanatory variables. In this paper, we depart from this, by explicitly modelling the change in concentration as being composed of two processes - size related growth and market share mobility. We then model the determinants of each of these components, together with the determinants of concentration, to see if the former adds to our understanding of why (and how) concentration changes. 
Our modelling strategy is based on the identity:

$$
\Delta H\left(\mathbf{s}_{t-1, t}\right) \equiv \operatorname{MOB}\left(\mathbf{s}_{t-1, t}\right)+\operatorname{SGRT}\left(\mathbf{s}_{t-1, t}\right) .
$$

The economic and technological drivers mentioned above (capital intensity, advertising, $R \& D$, growth and exports) can then be seen as affecting concentration through their effects on market share mobility on the one hand and size-related growth on the other. ${ }^{12}$ The explanatory variables in our econometric model fall into three classes: the standard IO variables, the variables reflecting dynamics and variables reflecting endogenous sunk costs.

\subsection{The Standard Model}

Traditional SCP models recognise structural, behavioural and performance-related drivers of market structure, which work either at the firm, or the industry, level. Our standard model includes:

KSR: The capital-sales ratio represents exogenous sunk costs through the capital intensity of the industry. In general, one might expect that in a high KSR industry, advantage falls to larger firms, increasing SGRT.

PROFIT: The return on sales measures profitability, which is both determined by market structure and, in turn, determines market structure ${ }^{13}$. An industry with above average PFT can be expected to encourage the entry and growth of smaller firms increasing MOB and decreasing SGRT.

EXPSR: The ratio of exports to sales, can feed back to domestic market shares, through learning and good practice, as well as through scale of operation. Typically, the smaller (of the large and medium) firms should be better placed to benefit in terms of leveraging exports to gain domestic market shares.

GROWTH: Growth of market size is measured as change in industry output between two years. In growing markets incumbents may find it difficult to occupy all the niches. New entry might be faster, and MOB greater. The effect on concentration will depend upon how agile small firms are in filling the niches that arise.

ASR: Industrial Organisation (IO) studies generally expect that brand loyalties will be reinforced by pre-emptive advertising campaigns, which in turn reinforce the existing monopolistic positions. From the point of view of our analysis in this paper, however, this would imply that there would be relatively little volatility and large firms may gain further, increasing SGRT.

The explanatory variables are annual median values across all firms in the industry for the year. It is worth making a methodological point. The endogeneity of the independent variables is a potential problem in most models involving firm behaviour and performance and has been well-recognised in the industrial organisation literature. This is true of the models in this paper too. Thus, while profitability may influence entry into an industry, this entry will in turn influence market shares of the firms and therefore will influence 
profitability. The same would be true of advertising and exports too. In this paper, we recognize this problem by lagging our right hand side variables as a number of other authors have done (Driffield and Kambhampati, 2003; Kambhampati and Parikh, 2004). Thus, while past profitability would influence current market structure (because it takes time for firms to respond to excess profits and enter the industry), the other relationship i.e. from market shares to profitability is a contemporaneous one i.e. current market share will influence current profits. This is true for a number of variables in the Structure-profits relationship and we have therefore lagged exports, advertising and R\&D.

\subsection{Dynamics}

As indicated earlier, one of the major drivers of structural change during this period was the liberalisation that was undertaken in the mid-1980s and then later in the early 1990s. This liberalisation may be expected to have a direct impact on market structure via entry into and exit from the industry. However, it may also have an impact by changing the way in which firms deploy certain behavioural expenditures (like advertising and R\&D) or take advantage of exports markets. To take the former into account, we include two dummy variables (D86 and D91) into our models. To take the latter into account, we allow these dummy variables to interact with each of our other behavioural variables (to see how, if at all, they change after the liberalisation). Thus, we have:

D86: which is a dummy variable and is $=0$ before 1986 and $=1$ for the years including and following 1986, marking out the domestic liberalisation.

D91: marks out the comprehensive liberalisation in 1991 and is a dummy variable $=0$ before 1991 and is $=1$ for the years including and following 1991 .

We also include D86 and D91 interacted with standard model variables (D86*ASR, D86*RDSR, D86*PROFIT and so on), to capture variations in the impacts of these variables after each of the liberalisation episodes.

In addition to these variables that attempt to capture the impact of liberalisation, we also include two other dynamic variables - Trend and Lag - to capture other longer-term dynamic patterns (see Kambhampati and Parikh, 2005 for a similar dynamic analysis). Trend captures the longterm trend and we also interact it with D86 and D91 to see if there are any changes or breaks in these trends following the two reforms periods. Finally, Lag attempts to control for autoregressive patterns in our variables.

\subsection{Endogenous Sunk Costs and Escalation}

Sutton (1991, 1998) has argued strongly that an increase in the toughness of competition prompts firms to competitively escalate (endogenous sunk cost) investment programmes, to move up the "quality" ladder. One would expect that in industries where endogenous sunk costs (such as Advertising and R\&D) are important, the essence of market selection will be that some firms will be more agile and effective in deploying these strategies than others. We should expect to see higher average values of advertising and R\&D intensity, having a larger impact on market structure and its components. To test for this, we included, ASR and RDSRin addition to the the standard model variables, 
RDSR: R\&D-sales ratio, capturing R\&D intensity of the industry. ${ }^{14}$

ASR*D86 and ASR*D91: to capture liberalisation induced trend shifts in the impact of advertising intensity.

RDSR*D86 and RDSR*D91: to capture liberalisation induced trend shifts in impacts of R\&D intensity.

It is worth mentioning that in exploratory work we attempted to capture the degree of escalation in these strategies in individual industries by including annual intra-industry dispersions of these variables - annual intra-industry inter-quartile ranges/variances of these variables. We found that these were not satisfactory proxies for the escalatory spread of strategy variable across firms within the industry, and dropped them from this final analysis.

\section{Results}

Our panel consists of data on 83 industries from 1980 to 1998 . We estimate separate models for SGRT and MOB, and use these to understand changes in concentration, which is also separately analysed. The data are a panel. and we estimate our model using both random and fixed effect methods. The Hausman test indicates that the fixed effects specification dominates the random effects in almost all cases. The time effects are clearly significant, and the models presented in Tables 1 and 2 are two-way error components models..

In addition to the above, we estimate two versions of our model - the full model and the restricted dynamic model. The full model includes both the standard IO variables as well as the dynamic variables (Table 1). The restricted dynamic model, on the other hand, includes only the dynamic variables and is presented in Table 2 . The model is estimated because the standard IO variables were found to be of very limited significance in the full model. Estimating the restricted dynamic model separately (as a model nested within the full model) allows us to test this hypothesis formally using a likelihood ratio test. We find that the likelihood ratio test is rejected in all 3 equations (SGRT, MOB and HHI) leading us to conclude that the standard IO variables do contribute to the explanation. However, their contribution is limited, and this is clear when we compare the values predicted by the restricted dynamic model to that of the full model (Figure 4). We therefore present these estimates as well in Table 2 below.

\subsection{Model Estimates}

Among the standard drivers of market structure, industry profit margins (PROFIT) induced larger firms to grow relative to smaller firms, and at the same time, decreased market share volatility. Advertising (ASR) benefited the growth of smaller firms, and increased market share volatility, while research and development $(\mathrm{R} \& D)$ benefited the growth of larger firms and decreased mobility. R\&D appears to have been a more effective barrier to small firm growth in India than advertising.

There were significant long-term trends in all three dependent variables - size-related growth, market share turbulence and in market concentration. Over the whole period, the size growth relationship trended upwards, suggesting an overall tendency for the larger firms to grow faster 
than the smaller, ceteris paribus. Likewise, there was a decreasing trend in market share mobility. This decline offsets the increase in size related growth in determining market concentration that shows a minuscule, but statistically significant, negative trend. 
Table 1: Full Model Estimation Results

\begin{tabular}{|l|c|c|c|c|c|c|}
\hline & \multicolumn{2}{|c|}{ HHI } & \multicolumn{2}{c|}{ MOB } & \multicolumn{2}{c|}{ SGRT } \\
\hline & & & & & \\
Variable & Coefficient & t-value & Coefficient & t-value & Coefficient & t-value \\
\hline DEPVAR(L) & $0.451 * * *$ & 18.78 & -0.026 & -0.87 & $-0.064^{* *}$ & -2.07 \\
TREND & $-0.007 * *$ & -2.31 & $-0.027 * * *$ & -3.84 & $0.033 * * *$ & 4.124 \\
GROWTH & 0.001 & 0.542 & -0.001 & -0.17 & 0 & 0.017 \\
PROFIT(L) & -0.062 & -1.52 & $-0.192 * *$ & -2 & $0.285 * *$ & 2.579 \\
KSR & -0.005 & -0.49 & 0.004 & 0.161 & 0.011 & 0.42 \\
EXPSR(L) & 0.014 & 0.103 & 0.153 & 0.477 & -0.068 & -0.18 \\
ASR(L) & $0.02 *$ & 1.79 & $0.089 * *$ & 3.329 & $-0.097 * * *$ & -3.16 \\
RDSR(L) & $-0.343 * *$ & -2.7 & $-0.651 * *$ & -2.19 & $0.977 * *$ & 2.851 \\
D86 & $0.074 *$ & 1.665 & $-0.19 *$ & -1.82 & 0.111 & 0.924 \\
TREND*D86 & -0.004 & -0.71 & $0.035^{* *}$ & 2.878 & $-0.031 * *$ & -2.24 \\
GRO*D86 & -0.011 & -1.33 & $-0.031 *$ & -1.67 & 0.024 & 1.138 \\
PFT(L)*D86 & -0.058 & -1.38 & 0.045 & 0.457 & 0.065 & 0.576 \\
KSR*D86 & 0.01 & 0.971 & -0.015 & -0.66 & -0.004 & -0.13 \\
EXPSR(L)*D86 & -0.125 & -0.87 & -0.323 & -0.96 & 0.309 & 0.795 \\
ASR(L)*D86 & 0.001 & 0.049 & $-0.078 * *$ & -2.11 & $0.07 *$ & 1.649 \\
RDSR(L)*D86 & 0.311 & 0.959 & -0.987 & -1.31 & 1.36 & 1.566 \\
D91 & $-0.112 * *$ & -2.28 & $0.338 * *$ & 2.961 & $-0.226 *$ & -1.72 \\
TREND*D91 & $0.011 * *$ & 2.401 & $-0.024 * *$ & -2.22 & 0.014 & 1.147 \\
GROWTH*D91 & 0.008 & 1.092 & $0.035 *$ & 1.967 & -0.027 & -1.33 \\
PROFIT(L)*D91 & 0.056 & 1.541 & -0.094 & -1.1 & 0.003 & 0.026 \\
KSR*D91 & -0.013 & -1.18 & 0 & 0.018 & 0.007 & 0.232 \\
EXPSR(L)*D91 & 0.004 & 0.05 & 0.051 & 0.25 & -0.105 & -0.44 \\
ASR(L)*D91 & 0.012 & 0.884 & -0.015 & -0.46 & 0.014 & 0.378 \\
RDSR(L)*D91 & 0.007 & 0.022 & $1.808 * *$ & 2.334 & $-2.513 * *$ & -2.82 \\
\hline Log L & 1227.4 & & 347.5 & & 163.4 & \\
Chi-Sq (b=0) & 2372.7 & & 412.2 & & 359.3 & \\
Hausman & 259.0 & & 114.2 & & 113.1 & \\
R2 & 0.84 & & 0.27 & & 0.24 & \\
Adj R2 & 0.83 & & 0.21 & & & \\
F & 275.0 & & 4.1 & & & \\
\hline
\end{tabular}

Note: (L) indicates that the variables are lagged once. 
Table 2: Restricted Model Estimation Results

\begin{tabular}{|l|c|c|c|c|c|c|}
\hline & \multicolumn{2}{|c|}{ HHI } & \multicolumn{2}{c|}{ MOB } & \multicolumn{2}{c|}{ SGRT } \\
\hline & & & & & & \\
Variable & Coefficient & t-value & Coefficient & t-value & Coefficient & t-value \\
\hline DEPVAR(L) & $0.457^{* * *}$ & 19.12 & -0.02 & -0.69 & $-0.053^{*}$ & -1.8 \\
TREND & $-0.006^{* *}$ & -2.08 & $-0.026^{* *}$ & -3.7 & $0.031^{* *}$ & 3.9 \\
D86 & 0.049 & 1.125 & $-0.214^{* *}$ & -2.15 & 0.187 & 1.625 \\
TREND*D86 & -0.002 & -0.46 & $0.034^{* *}$ & 2.874 & $-0.034^{* *}$ & -2.49 \\
D91 & $-0.081^{* *}$ & -1.66 & $0.326^{* *}$ & 2.929 & $-0.277^{* *}$ & -2.15 \\
TREND*D91 & $0.009 * *$ & 1.922 & $-0.024^{* *}$ & -2.3 & 0.019 & 1.581 \\
\hline Log L & 1411.0 & & 325.1 & & 135.2 & \\
Chi-Sq (b=0) & 2739.4 & & 367.5 & & 302.9 & \\
Hausman & 245.3 & & 106.7 & & 101.6 & \\
R2 & 0.88 & & 0.25 & & 0.21 & \\
Adj R2 & 0.87 & & 0.19 & & 0.15 & \\
F & 96.4 & & 4.4 & & 3.5 & \\
\hline
\end{tabular}

The 1985 liberalisation (D86*TREND) reversed the trend in size-related growth, suggesting that smaller firms gained in this period. This was accompanied by a step up in the level of market share turbulence. The 1991 liberalisation seemed to have had no significant impact on size-related growth, but it influenced the level of mobility. MOB stepped up in 1991 (positive D91) and from this high point, declined in trend. Growth in market size also had a significant positive impact on MOB after 1991. It is of course possible that size related growth (SGRT) could be independent of market shares, because with growth of market size in the new environment, in principle, any firm could have grown - liberalisation accommodates growth of all firms. In this context, firms that are quick off the mark will be the ones that are "able" to grow in this new liberalised but competitive climate. We therefore did not presuppose any particular sign for SGRT.

It is notable that neither of the liberalisation episodes led to any significant change in the impact of profit margins, capital use, advertising, or exports on market structure or its components. Amongst behavioural variables, only $R \& D$ has a significant differential in the second liberalisation episode. Although the R\&D intensity benefited large firms (see above), after the 1991 liberalisation, its impact shifted in favour of smaller firms, increasing mobility as well.

Since our estimations indicate that the dynamic variables (lags, trend and liberalisation dummies) were by far the most significant variables in these models, we re-estimated the models including only the dynamic variables (see Restricted Dynamic Model in Table 2). The likelihood ratio test of the unrestricted against the restricted model shows the restrictions to be significant. However, we present these results because our simulations indicate that in the presence of significant structural changes, the contribution of standard IO variables to the explanation of market structure diminishes and the role of dynamic changes becomes more significant. This, of course, is not surprising, given that most IO models assume mature economies with stable (if not equilibrium) market structures. In spite of this result, we present the models both with and without the structural variables. The former is the standard IO model and it is interesting to see what impact these variables have in a dynamic, fast changing economy like India. The latter has only the time- and reform related variables. We tried to maintain the same specification for all 3 models because we - prima facie- expect similar driving forces to be active in working upon these structural aspects industry. 


\subsection{Implications of results}

To secure an overall picture we present the annual conditional mean values predicted by the models in Table 1. Figure 3 presents predicted values of SGRT and MOB, and compares them with the change in HHI that arises from these predictions. SGRT and MOB on the other hand have very pronounced dynamic patterns, but they offset each other; as a result, annual changes in HHI are very small.

Figure 3: Trends in Conditional means of Concentration, Size-Growth and Mobility

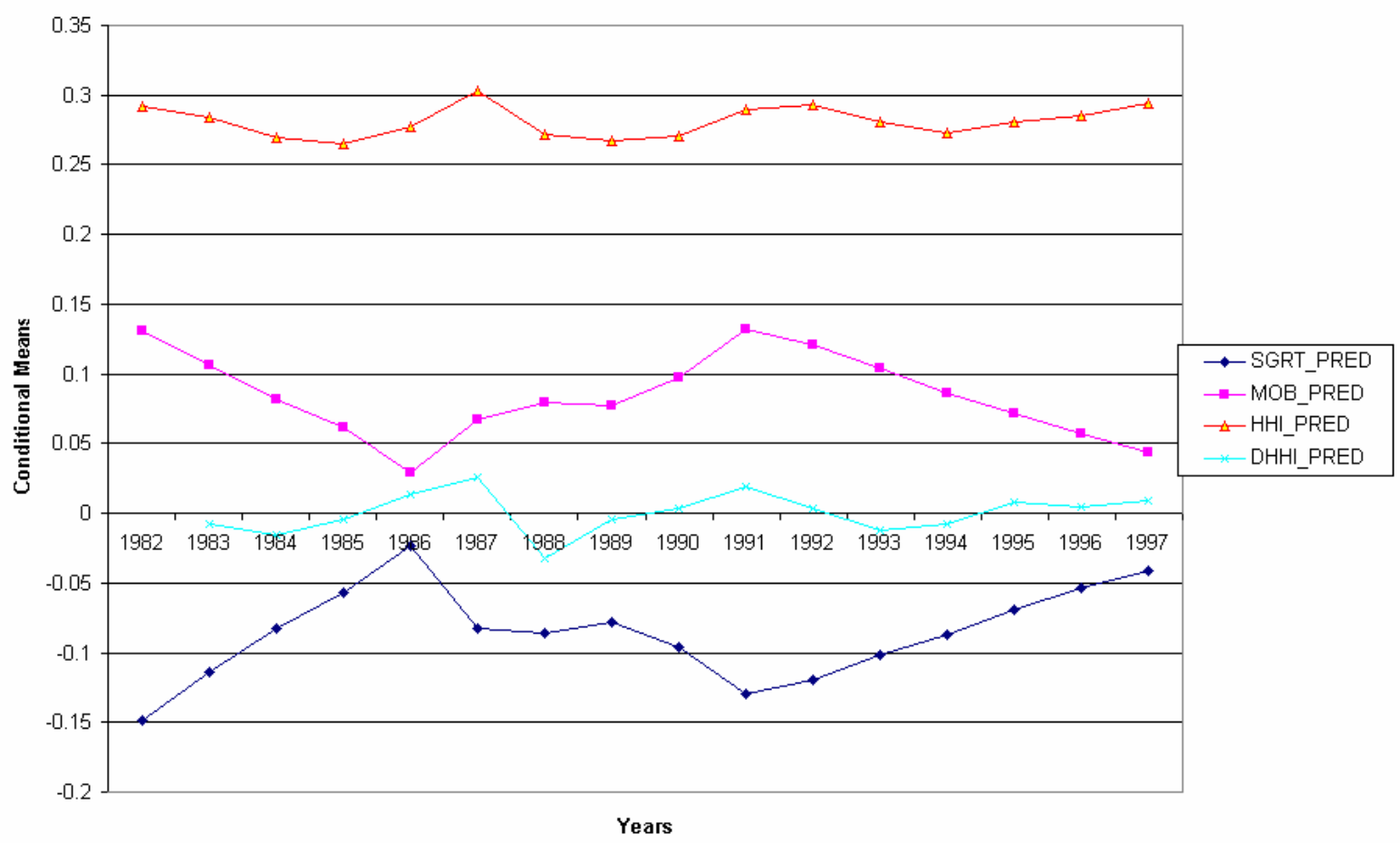

An observer looking only at HHI and its change might have inferred that little of import happened with either episode of liberalisation. In fact, much did happen. Prior to 1985, larger firms were growing faster (SGRT was rising) and market share volatility (MOB) was in decline. The changes in direction in SGRT and MOB were reversed in the domestic liberalisation phase - SGRT fell and MOB rose; suggesting that smaller firms were quicker to take up new opportunities in an environment that was partially protected. These trends were reversed again in the comprehensive liberalisation phase, SGRT rose and MOB fell, suggesting that larger firms fared better than the smaller in the more competitive and turbulent environment of the 1990s 
Figure 4: Mobility and Size-Growth: Trends in Conditional means

from the full model and Restricted (dynamics) model

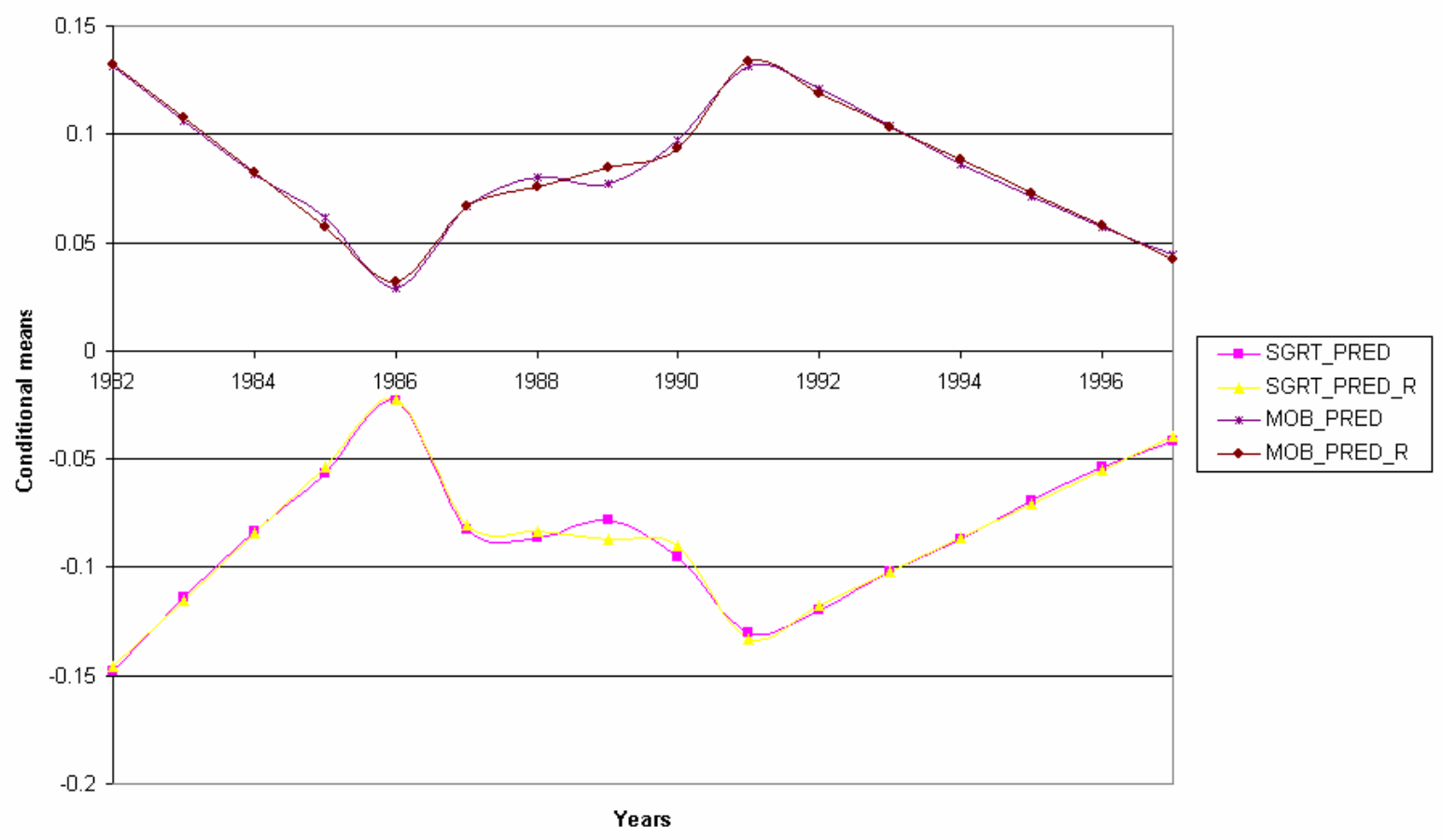

Figure 4 shows that restricted models including only the dynamics terms (LAG, TREND, D86, D91, D86*TREND, D91*TREND) decompose the mean tendencies of MOB and SGRT into constituents: the standard model and the dynamics. In both cases, the dynamics has most of the explanatory power of the full model. The trends are captured almost entirely.

\section{Conclusions}

From the point of view of the literature on the determinants of market structure, we have sought to revisit the difference between concentration and turbulence as measures of competition. The standard interpretation would lead us expect lower concentration with liberalisation, and increased market share churning. But increased turbulence, ipso-facto, increases concentration, and it is the change in size-growth relationship that drives a wedge between the two. If concentration declines while turbulence increases that will necessarily be because in the reallocation of market shares, agile smaller firms are the gainers. The need to iron out capital market imperfections that hamper the growth of efficient small firms stands out as a conclusion.

Two factors distinguish this paper from others in this field. First, we consider the determinants of market structure in terms of the determinants of its components - size-related growth and mobility. Figure 1 confirms the usefulness of this decomposition; in India both the size-growth relationship and market share mobility changed considerably in response to the two liberalisation episodes. By virtue of their offsets, the net effect of liberalisation on concentration was small. Examining market structure changes alone would have led us to underestimate the impact of liberalisation on processes driving market structure. It also further strengthens the need for a change in methodology away from a consideration of market structure alone towards a consideration of the components of this change. 
Detailed knowledge of the patterns of movement of these decomposed variables should help to make industrial policy more focussed and relevant.

The second relates to our findings rather than our methodology. Contrary to other papers in the field, we find that the dynamic variables (structural breaks, trends and lags) explain most of the changes in the components of market structure. This is not surprising, because the standard industrial organisation model relates to mature (and close to equilibrium) market structures, whereas the economies in transition in general (the Indian economy from the mid 1980s and 1990s) were arguably far from equilibrium. It is not surprising that structural changes that are absorbed into the dynamics of liberalisation turn out to explain much of the changes in market structure, dwarfing the effects of the limited set of observable driving variables considered in the model. 


\section{Appendices}

\begin{tabular}{|l|c|c|c|c|c|c|c|c|c|c|}
\hline \multicolumn{10}{|c|}{ Table A1: Summary Statistics } \\
\hline & \multicolumn{3}{|c|}{ Mean } & \multicolumn{3}{c|}{ Standard deviation } & \multicolumn{3}{c|}{ Skewness } \\
\hline & $1982-85$ & $1986-90$ & $1991-97$ & $1982-85$ & $1986-90$ & $1991-97$ & $1982-85$ & $1986-90$ & $1991-97$ \\
\hline HHI & 0.269 & 0.287 & 0.279 & 0.226 & 0.240 & 0.235 & 1.638 & 1.372 & 1.441 \\
SGRT & -0.088 & -0.094 & -0.078 & 0.279 & 0.244 & 0.236 & -4.876 & -3.985 & -4.729 \\
MOB & 0.083 & 0.098 & 0.078 & 0.259 & 0.221 & 0.214 & 4.979 & 3.926 & 4.840 \\
\hline GROWTH & 0.396 & 0.493 & 0.394 & 2.161 & 5.865 & 4.058 & 12.565 & 23.245 & 31.557 \\
PROFIT & 0.306 & 0.331 & 0.314 & 0.163 & 0.161 & 0.178 & 0.923 & 1.324 & -2.550 \\
KSR & 0.703 & 0.700 & 0.765 & 0.591 & 0.569 & 1.528 & 3.628 & 7.472 & 23.462 \\
EXPSR & 0.012 & 0.025 & 0.019 & 0.027 & 0.072 & 0.062 & 3.212 & 5.940 & 6.807 \\
ASR & 0.187 & 0.264 & 0.216 & 0.473 & 0.716 & 0.573 & 3.894 & 6.439 & 6.583 \\
RDSR & 0.008 & 0.031 & 0.016 & 0.043 & 0.080 & 0.059 & 6.007 & 3.750 & 5.168 \\
\hline
\end{tabular}




\begin{tabular}{|c|c|c|c|c|c|}
\hline \multicolumn{6}{|c|}{ Table A2: List of Industries } \\
\hline Code & Industry Name & Code & Industry Name & Code & Industry Name \\
\hline 110 & Tea Plantations & 420 & Aluminium & 470 & Matches \\
\hline 120 & Coffee Plantations & 430 & Other non-ferrous metals (Basic) & 490 & Miscellaneous \\
\hline 130 & Rubber Plantations & 441 & Automobile - vehicles & 510 & Mineral oils \\
\hline 190 & Misc. Plantations & 442 & Automobile - Components etc.. & 521 & Cement (hydraulic) \\
\hline 210 & coal mining & 443 & Railway equipments & 522 & Asbestos \& As. Cement prods \\
\hline 220 & Metal Mining & 444 & Other Transport equipments & 531 & Structural clay products \\
\hline 230 & Petroleum Mining & 445 & Cables & 532 & Pottery,china \& earthenware \\
\hline 290 & Other Mining & 446 & Dry Cells & 541 & Tyres and tubes \\
\hline 310 & Grains \& Pulses & 447 & Electric Lamps & 542 & Other rubber products \\
\hline 320 & Edible oils & 448 & Other Electrical Machinery & 551 & Paper \\
\hline 331 & Sugar & 449 & Machine Tools & 552 & Products of pulp \& board \\
\hline 332 & Other food products & 450 & Textile Machinery and parts & 553 & Wood products and furniture \\
\hline 341 & Cigarette & 451 & Misc. Mechinery & 561 & Glass containers \\
\hline 342 & Other tobacco & 452 & Steel tubes $\&$ pipes & 562 & Other Glass products \\
\hline 351 & Cotton Textiles - Spg. & 453 & Steel Wire ropes & 571 & Printing \\
\hline 352 & Cotton Textiles - Wvg. & 454 & Steel Forgings & 572 & Publishing \\
\hline 353 & Cotton Textiles - Comp & 455 & Foundries and Engg. Workshops & 573 & Printing, Publishing etc. \\
\hline 354 & Cotton Textiles - Others & 456 & Aluminium Ware & 580 & Plastic products \\
\hline 355 & Jute Textiles & 457 & Other Ferrous / non-ferrous metal & 589 & Diversified \\
\hline 356 & Silk \& Rayon Textiles - Spinning. & 461 & Chemical Fertilisers & 590 & Miscellaneous \\
\hline 357 & Silk \& Rayon Textiles - Weaving. & 462 & Dyes \& Dyestuff & 610 & Construction \\
\hline 358 & Silk \& Rayon Textiles - Composites & 463 & Man made fibres & 620 & Electricity generation and supply \\
\hline 359 & Woolen Textiles & 464 & Plastic Raw materials & 640 & Trading \\
\hline 360 & Ginning, pressing & 465 & Other basic industrial chemicals & 650 & Land \& Estate \\
\hline 370 & Breweries \& Distilleries & 466 & Medicines \& Pharma. preps & 660 & Road Transport \\
\hline 380 & Leather \& Leather products & 467 & Paints, Varnishes etc. & 670 & Shipping \\
\hline 390 & Miscellaneous & 468 & Other chemical products & 680 & Hotels, restaurants \\
\hline 410 & Iron \& Steel & 469 & Industrial \& medical gases & 690 & Miscellaneous \\
\hline
\end{tabular}




\section{Notes}

1 They used a framework that integrated market concentration and market share turbulence to determine which of the two stylised facts captured the true picture of competitive rivalry. For the UK they analysed how the dynamics of market shares of largest firms feed into the concentration ratio $(\mathrm{C} 5)$.

However, reservations for small-scale industry continued. While the government also accepted the need for redundancies, and began a process of withdrawal from involvement in employer-employee negotiations, few significant steps have been taken towards the removing exit barriers.

3 There has been considerable work on the growth results of reforms - Joshi and Little (1994), Ahluwalia (2002), Srinivasan and Tendulkar (2003) and Desai (1990).

Away from metal based and heavy machinery sectors towards electrical machinery, chemicals, non-metallic mineral products and products such as leather, rubber, plastics and petroleum products.

Entry and Exit can be accommodated by letting $\mathrm{s}_{\mathrm{it}-1}$ or $\mathrm{s}_{\mathrm{it}}$ as appropriate, to be 0 .

SGRT can be written in terms of the $\beta$ coefficient of a cross-sectional mean reversion equation. Consider a linear cross sectional relationship $\Delta s_{i}=\alpha+\beta s_{i t-1}+\varepsilon_{i}$. (This is the Galtonian regression model - in terms of market shares rather than log size. If the distribution of $s_{i t}$ is skewed, the estimation results would be dominated by the largest firms. In our context, with the focus on public companies, the distribution is less skewed than the case with all firms.) Such a regression provides an estimate of the degree of "mean reversion" (or converse) as the cross section evolves. The sign and magnitude of $\hat{\beta}$ tells us whether firm sizes are reverting to mean size, or whether larger firms are growing larger. Since the OLS estimate $\hat{\beta}=\operatorname{Cov}\left(s_{i t-1}, \Delta s_{i}\right) / V\left(s_{i t-1}\right)$ the last term in the RHS can be rewritten in terms of the mean reversion coefficient, as: $2 \hat{\beta} V\left(s_{i t-1}\right)+n E\left(s_{i t-1}\right) E\left(\Delta s_{i}\right)$. Alternative ways in which this term can be written are: $2 \hat{\beta} \sigma^{2}\left(s_{i t-1}\right)+1 / n-H(\mathbf{s})$, and $\rho \sigma\left(s_{i t}\right) \sigma\left(s_{i t-1}\right)+1 / n-H(\mathbf{s})$ where $\rho$ is the correlation coefficient between market shares at date $\mathrm{t}-1$ and date $\mathrm{t}$.

As MOB includes all market share changes, this includes both (a) the case of large firms further increasing their market shares (regression away from the mean) as well as (b) the case of small firms increasing their market shares, which sometimes carries the specific connotation of mobility.

It is easy to see that concentration, proxied Variance of market shares can increase even when small firms grow faster, $\beta<1$, if $V\left(\varepsilon_{i t}\right)$ offsets the tendency : $V\left(s_{i t}\right)=\beta^{2} V\left(s_{i t-1}\right)+V\left(\varepsilon_{i t}\right)$.

The data set provides no information on the variety of products produced by a firm or on coverage ratios. Earlier studies (Shanker, 1988; Siddharthan, 1981) have indicated that firms in India tend to diversify narrowly (within the same 3 digit industry category) though 
industry houses span wider industries. Government licensing also played a role in maintaining such a narrow range of diversification. Given this, it looks likely that, though firms may produce a number of different products, these products are likely to fall within the same industry group.

For example, the combined balance sheet analysis based on the data published by the RBI in 1993 (Bulletin, December) reported results for 1988-89, 1989-90, and 1990-91 based on a sample of 2131 companies. A similar analysis in 1992 (Bulletin, November) reported results for 1908 companies for 1987-88, 1988-89 and 1989-90. The two samples had 1647 companies in common.

There is the implicit assumption that the method by which successive samples are selected should not have undergone a change. For further details on the extent of coverage for each sample survey ref. Uma Datta Roy Chaudhari (1992) pp. 599, 616 and 643.

An alternative method, one we do not pursue here would be to estimate a system of equations imposing the identity as a restriction.

This two-way causality is common to many variables included in IO studies. We take account of it here by lagging the variables, where appropriate. Thus, our model includes lagged values of PROFIT, ASR and RDSR, on the grounds that it would take time for entry (or a barrier to entry) to influence market structure. 


\section{References}

Ahluwalia, I.J. (1985). Industrial Growth in India: Stagnation Since the Mid-1960s, Delhi: Oxford University Press.

Ahluwalia, I.J., Mohan, R. and Goswami, O. (1996). Policy Reform in India, Delhi: Oxford and IBH Publishing Co. Pvt. Ltd.

Ahluwalia, M. (2002). Economic Reforms in India since 1991: Has Gradualism worked? Journal of Economic Perspectives, 16(3), pp. 67-88.

Athreye, S.S. and Kapur, S. (2005)

Basant, R. and Chandra, P. (2002). Building Technological Capabilities in a Liberalising Developing Economy: Firm Strategies and Public Policy, Economics of Innovation and New Technology, 11(4-5), pp. 399-421.

Basant, R. (2000). Corporate Response to Economic Reforms, Economic and Political Weekly, March 4, pp. 813-22.

Bhaduri, A. and Nayyar, D. (1996). The Intelligent Person's Guide to Liberalisation, Penguin, India.

Bhagwati, J. and Desai, P. (1970). India: Planning for Industrialization, Delhi: Oxford University Press.

Bhagwati, J. and Srinivasan, T.N. (1975). Foreign Trade Regimes and Economic Development: India, National Bureau of Economic Research, New York

Cable, J. (1997). Market Share Behavior and Mobility: An Analysis and Time-Series Application, Review Of Economics and Statistics, 79(1), pp. 136-41.

Chand, S. and Sen, K. (2002). Trade Liberalisation and Productivity Growth: Evidence from Indian Manufacturing, Review of Development Economics, 6(1), pp. 120-32.

Chandra, P. and Sastry, T. (1998). Competitiveness of Indian Manufacturing: Findings of the 1997 Manufacturing Futures Survey, Vikalpa, 23 (3), pp. 25-36.

Datta Roy Chaudhari, U. (1992), Journal of Indian School of Political Economy, Vol.4 No.4.

Davies, S. and Geroski, P. (1997). Changes in Concentration, Turbulence, and the Dynamics of Market Shares, Review of Economics and Statistics, 79(3), pp. 383-91.

Desai, A. (1999). The Economics and Politics of Transition to an Open Market Economy: India, OECD Working papers, Volume VII, No. 100.

DeLong, J. B. (2001). India since Independence: An Analytical Growth Narrative, in Rodrik, D. (ed.) Modern Economic Growth: Analytical Country Studies.

Driffield, N., and Kambhampati, U.S., 2003, 'Efficiency of Firms in Indian Industry: The Effect of Reforms,' Review of Development Economics, Vo.7, No.3, pp.419-430.

Ghemawat, P. and Kennedy, R. (1998). Competitive Shocks and Industrial Structure: The Case of Polish Manufacturing, International Journal of Industrial Organization, 17(6), pp. 847-67.

Ghemawat,P. and Khanna, T. (1998). The Nature of Diversified Business Groups: A Research Design and Two Case Studies, Journal of Industrial Economics, 46 (1), pp. 35-61.

Government of India (1986). Economic Survey, 1985/6, Ministry of Finance, New Delhi.

Joshi, V. and Little, I.M.D. (1996). India's Economic Reforms: 1991-2001, Delhi, OUP

Kambhampati,U.S. (1996). Industrial Concentration and Performance: A Study of the Structure, Conduct and Performance of Indian Industry, Delhi: Oxford University Press.

Kambhampati,U.S., and Parikh,A., 2005, 'Has Liberalisation Affected Profit Margins in Indian Industry?,' Bulletin of Economic Research.

Panagariya, A. (2004). Growth and Reforms during 1980s and 1990s, Economic and Political Weekly, XXXIX (25), pp. 2581-2594.

Patibandla, M. (1998). Structure, Organizational Behaviour, and Technical Efficiency: The Case of an Indian Industry,' Journal of Economic Behaviour and Organization, 34, pp. 419-434. 
Patibandla, M. (2002). Policy Reforms, and Evolution of Market Structure in an Emerging Economy, Journal of Development Studies, 38(3) pp. 95-118.

Reserve Bank of India (1992) Bulletin, November.

Reserve Bank of India (1993) Bulletin, December.

Roy Chaudhury, U.D. (1992), Journal of Indian School of Political Economy, 4(4), pp. 599 - 616

Shanker, K., (1988). Product Diversification, Growth and Profitability in the Private Corporate Sector in India, Reserve Bank of India Occasional Papers, 9(3) pp. 281-97.

Siddharthan, N.S. (1981). Conglomerates and Multinationals in India: A Study of Investment and Profit, New York: Mc Graw Hill Book Company Ltd.

Srinivasan, T.N., and Tendulkar, S. (2002). Reintegrating India with the World Economy, Institute for International Economics, Washington, DC..

Srivastava, V., (1996). Liberalization, Productivity and Competition, Delhi: Oxford University Press.

Sutton,J., (1991). Sunk Costs and Market Structure : Price Competition, Advertising, and the Evolution of Concentration, Cambridge, Mass.: MIT Press.

Sutton,J., (1997). Gibrat's legacy, Journal of Economic Literature, Vol. XXXV, pp. 40-59.

Sutton, J., (1998). Technology and Market Structure: Theory and History, Cambridge, Mass London: MIT Press. 